\title{
Um Modelo Alternativo para a Cognição Direta de Estados Mentais Elementares de Terceiros
}

\author{
[An Alternative Model for Direct Cognition of Third-Party Elementary Mental States]
}

\section{Roberto Horácio de Sá Pereira®}

Resumo: Meu objetivo consiste em desenvolver um modelo teórico alternativo para a cognição direta dos estados elementares de terceiros à chamada Teoria da Interação (doravante TI), também conhecida como abordagem da "segunda pessoa". O modelo que proponho emerge de uma reformulação crítica do modelo de percepção deslocada (displaced perception) proposto por FRED DRETSKE (1995), entretanto, para o conhecimento introspectivo dos próprios estados mentais. Contra Dretske (1995), sustento, primeiro, que o conhecimento das emoções básicas não depende de crenças chamadas "crenças conectivas" que sugerem, contra o ele mesmo pretende, uma indução empírica. Ademais, contra Dretske, sustento que nenhuma meta-representação (representação de segunda ordem de uma representação de primeira ordem como uma representação) está envolvida no processo, mas apenas conceitos bastante rudimentares das emoções de terceiros: contentamento e descontentamento. A rigor, todos os dados e achados empíricos oriundos da psicologia do desenvolvimento apoiam apenas a hipótese de que criança em fase pré-linguística compreende perceptualmente (ou seja, de forma não mediada por inferências) expressões faciais básicas de contentamento e descontentamento. A minha proposta alternativa consiste então no seguinte. A percepção direta dos estados mentais elementares de terceiros não é uma percepção em sentido usual do termo segundo o qual percebemos coisas, mas uma "percepção de fatos". Mas como entende-la? Ela nada mais é do que um processo epistemológico ao mesmo tempo automático e confiável. É confiável no sentido externista-epistemológico de não envolver nenhuma inferência, reflexão, teorização ou justificativa epistêmica: a percepção do bebê da expressão facial do descontentamento da mãe (percepção usual de algo) não constitui nenhuma razão em favor da "crença" que a mãe está descontente. A própria palavra "crença" não deve ser entendida no sentido usual, mas no sentido de uma inclinação natural pela verdade. Mas é ao mesmo tempo automático porque a crença é a resultante ou output de um processo inteiramente subliminar de natureza computacional. Assim, por exemplo, uma criança percebe que a sua mãe está descontente (fact-awareness) ao perceber de forma consciente ("percepção" em sentido usual) a expressão facial de descontentamento (input sensorial), mas reconhece que a mãe está descontente como o resultado (output) de um processo inteiramente subliminar.

Palavras-chave: Enactivismo. Teoria da Interação. Teoria da Teoria. Teoria da Simulação. Corpos Estendidos.

${ }^{\star}$ Professor titular da Universidade Federal do Rio de Janeiro (UFRJ). Bolsista de Produtividade em Pesquisa do CNPq - Nível 1C. E-mail: robertohsp@gmail.com. ORCID: https://orcid.org/0000-0002-9117-0755. 


\begin{abstract}
My aim is to develop an alternative theoretical model for the direct cognition of the elementary states of others called the theory of interaction (henceforth TI), also known as the "second person" approach. The model I propose emerges from a critical reformulation of the displaced perception model proposed by FRED DRETSKE (1995) for the introspective knowledge of our own mental states. Moreover, against Dretske, I argue that no meta-representation (second order representation of a first order representation as a representation) is involved in the process, but only concepts, rudimentary enough, of others' emotions: contentment and discontentment. Strictly speaking, all the empirical data and findings in developmental psychology only support the hypothesis that children in pre-linguistic phase understand perceptually facial expressions of contentment and discontentment. My proposal consists in the following thesis: The direct perception of others elementary mental states is not a perception in the usual sense of the word according to which we just perceive things, rather a "perception of facts". But how to understand that? It is nothing more than an epistemological process automatic and reliable at the same time. It is reliable in the epistemological-externalist sense of not involving any inference, reflection, theorizing or epistemic justification: a baby's perception of her mom's facial expression of discontentment (in the usual sense of "perception") does not constitute a reason supporting the belief that mommy is discontent. The very word "belief" should not be understood in the usual sense, rather in the sense of a natural inclination for truth. But at the same time, it is automatic because the belief is a result or output of a process entirely subliminal and computational in nature. Thus, for instance, a child perceives that her mom is discontent (fact-awareness) by perceiving consciously ("perception" in the usual sense) a facial expression of discontentment (sensorial input) but recognizes that her mother is discontent as a result (output) of an entirely subliminal process.
\end{abstract}

Keywords: Enactivism. Interaction Theory. Theory Theory. Simulation Theory. Extended Body. 


\section{Introdução}

O debate sobre cognição da mente de terceiros se concentrou por um bom tempo, no conflito entre as chamadas teorias da teoria (TT) e teorias de simulação (ST) como formas interpretações da mente (mindreading). A TT toma a forma inequívoca de uma teoria em terceira pessoa, enquanto a ST a forma de uma teoria em primeira pessoa. Recentemente SHAUN GALLAGHER (2008) e DAN ZAHAVI (2011) sustentaram que deveríamos abandonar tanto as abordagens de terceira pessoa, Teoria da Teoria (TT doravante), como as abordagens e de primeira pessoa (Teoria da Simulação) em favor do que eles denominam "abordagem da segunda pessoa", "modelo de percepção direta" (MPD), ou ainda "Teoria da Interação" (doravante TI). Por razões de praticidade, utilizarei a última nomenclatura, a Teoria da Interação ou TI. ${ }^{1}$

É notório que a TI nada mais é do que o desdobramento da chamada concepção enativista da percepção também conhecida como "cognição incorporada", aplicada agora ao conhecimento de outras mentes. Ainda nessa breve introdução, gostaria de destacar o menos quatro teses da TI três são dignas de nota. 1- Estados mentais de terceiros não estariam "ocultos pelas suas condutas", mas percebidos diretamente. 2-
Por essa razão, a cognição de tais estados seria perceptual (ou direto) e não inferencial (ou indireto). 3- Entretanto, como uma explicação parcial da cognição incorporada, exige-se que a percepção humana tenha um "certo tipo de sofisticação" ou, nas palavras de Gallagher, "inteligência" (Smartness). 4Mas a quarta tese é a fundamental uma vez que estabelece a conexão direta entre TI e o enactivismo. Ela reza o seguinte: a percepção direta dos estados de terceiros é "social" no sentido que é produto de corpos humanos que agem e interagem. É importante se ter claro que, segundo a TI, tais "corpos em ação" preexistem e são independentes das representações neuronais dos mesmos corpos envolvidos. Sem tal suposição tanto a TI quanto o enactivismo se resumiriam a teses absolutamente triviais pois ninguém nega que corpos humanos estejam envolvidos na cognição de objetos e de terceiros.

Nesse trabalho, endosso a primeira das três grandes teses: ao menos no tange estados mentais elementares de terceiros (emoções elementares), o conhecimento é perceptual e não inferencial. No que tange ao conhecimento de estados mentais de terceiros (incluindo aí criaturas não humanas), a minha posição é abdutiva: se uma simples abelha possui mente ou não, tenho que levar tudo em consideração sobre o que hoje

\footnotetext{
${ }^{1}$ A literatura é vasta e não há espaço aqui para discuti-la em detalhe. Conferir CASSAM 2007; DRETSKE 1973; GALLAGHER 2004, 2008; 2012; GRENN 2010; HUSSERLS 1995; KRUEGEL 2012; MCDOWELL 2009; MCNEILL 2012; RATCLIFFE 2007 ; ZAHAVI 2011.
} 
sabemos: intuições pré-teóricas, neurofisiologia, comportamento, TT TS etc. etc. Mas por que endosso a suposição de que o conhecimento de estados emocionais de terceiros seja direto no sentido de ser não inferencial?

Porque abundam evidências empíricas da psicologia do desenvolvimento que infirmam tanto a TT quanto a TS. Bebês compreendem, ainda que de uma forma bastante rudimentar, expressões faciais dos seus cuidadores de contentamento e descontentamento muito antes de serem capazes de refletir, erigir hipóteses (TT) ou mesmo de simular (TS) qualquer coisa. A esse respeito, me junto à grande tradição fenomenológica de MAURICE MERLEAU-PONTY para a qual tanto TT quanto TS e a tradicional teoria da Analogia são formas descabidas de intelectualismo. Mas como veremos, a situação dos bebês diante dos seus cuidadores não é essencialmente distinta da situação dos cães domésticos diante dos seus humanos e dos demais cães.

Entretanto, é importante que se deixe claro, logo de início, que "percepção direta" não deve ser entendida no sentido usual em que percebemos objetos ou estados mentais de terceiros empiricamente. A palavra "percepção" tem aqui um sentido metafórico que remonta aos trabalhos de FRED DRETSKE em 1973, 1995, e 1999. "Percepção direta" deve ser entendida aqui como "percepção de fatos" (fact-awareness), ou seja, fundamentalmente como uma forma de cog- nição que dispensa inferências, e com elas reflexão, hipóteses, teorizações e simulações como nos modelos TT e TI. Dito, isso, rejeito todas as demais teses da TI. A rigor, meu principal ponto de divergência com a TI é o próprio enactivismo (da qual ela nada mais é do que um desdobramento). Buscarei demonstrar que nenhuma tese enativista é plausível.

Esse artigo tem por objetivo desenvolver um modelo teórico alternativo para a cognição direta dos estados elementares de terceiros à chamada Teoria da Interação (doravante $\mathrm{TI}$ ), também conhecida como abordagem da "segunda pessoa". O modelo que proponho emerge de uma reformulação crítica do modelo de percepção deslocada (displaced perception) proposto por Dretske (1995), entretanto, para o conhecimento introspectivo dos próprios estados mentais. Contra Dretske (1995), sustento, primeiro, que o conhecimento das emoções básicas não depende de crenças chamadas por ele denominadas de "conectivas" que sugerem, contra o ele mesmo pretende, uma indução empírica. Ademais, contra Dretske, sustento que nenhuma meta-representação (representação de segunda ordem de uma representação de primeira ordem como uma representação) está envolvida no processo, mas apenas conceitos bastante rudimentares das emoções de terceiros: contentamento e descontentamento. A rigor, todos os dados e achados oriundos da 
psicologia do desenvolvimento apoiam apenas a hipótese de que criança em fase pré-linguística compreende perceptualmente (de forma não mediada por inferências) expressões faciais básicas dos seus cuidadores como expressões de contentamento e de descontentamento.

Segundo a minha proposta alternativa a percepção direta dos estados mentais elementares de terceiros nada mais é do que um processo epistemológico ao mesmo tempo automático e confiável. É confiável no sentido externista-epistemológico de não envolver nenhuma inferência, reflexão, teorização ou justificativa epistêmica: a percepção do bebê da expressão facial de descontentamento da mãe ("percepção" no sentido usual de algo) não constitui nenhuma razão ou evidência em favor da "crença" que a mãe está descontente. A rigor, a própria palavra "crença" não deve ser entendida no sentido usual, mas no sentido de uma inclinação natural pela verdade, que independente de reflexão ou avaliação crítica. Mas é ao mesmo tempo automático porque a crença é o resultado ou output de um processo inteiramente subliminar/computacional. Assim, por exemplo, uma criança percebe que a sua mãe está descontente (factawareness) ao perceber de forma consciente ("percepção" em sentido usual) a expressão facial de descontentamento (input sensorial), mas reconhece (factawareness) que a mãe está descontente como o resultado (output) de um processo inteiramente subliminar.

$\mathrm{O}$ artigo está concebido da seguinte forma. Na seção que se segue a essa introdução, apresento, em linhas gerais, as duas teorias contemporâneas sobre o conhecimento da mente de terceiros que monopolizaram o debate recente desde o ocaso do behaviorismo e da teoria da inferência analógica, são elas a chamada Teoria da Teoria (doravante TT) e a Teoria da Simulação (doravante ST). A seção seguinte está consagrada à apresentação e à crítica da teoria da interação (doravante TI). A seção subsequente está dedicada especificamente a uma crítica à sugestão de Gallagher de que a tal percepção "direta" dos estados de terceiros tenha que ser ao mesmo tempo inteligente (Smart) e epistêmica.

Como TI se apoia explicitamente na teoria enativistas da experiência perceptual, a seção subsequente tem a pretensão de demolir uma a uma todas as teses enativistas. A conclusão a que chego nesse trabalho é a de que teoria da interação nada possui de recomendável. A única ideia que resta de pé (nunca negada pelos representacionistas em filosofia da mente nem cognitivistas nas ciências cognitivas) é a de que conhecemos estados mentais elementares de terceiros de forma imediata. Assim, na última seção, apresento uma explicação alternativa para tal fato empírico bruto. Como antecipei, essa explicação consiste em uma reelaboração crítica do modelo de percepção des- 
locada ou secundária apresentada por Dretske em 1973/1995.

\section{TT e ST}

A pesquisa interdisciplinar sobre cognição da mente de terceiros normalmente toma a forma do que se poderia chamar de "leitura mental" (mindreading), ou seja, uma "teoria da mente" tal como um sistema de representações que formamos sobre os estados mentais de terceiros. $\mathrm{O}$ mindreading emerge do fracasso retumbante do chamado behaviorismo psicológico e da teoria da analogia que remonta a JOHN STUART MILL (1865 [1872: 243]), mas que foi endossada até o século vinte por filósofos proeminentes como BERTRAND RUSSELL (1923), STUART HAMPSHIRE (1952) e ALFRED JULLES AYER (1956, pp. 219-222). Segundo o segundo modelo, conheceríamos estados mentais de terceiros com base em uma inferência analógica em primeira pessoa: como a minha dor causa meu comportamento típico de quem tem dor, ao observar tal comportamento, eu teria legitimidade para concluir que outrem também tem dor. A analogia fracassa por três razões elementares. Primeiro, trata-se de uma inferência de um caso único; segundo não há checagem independente da conclusão; terceiro, como podería- mos ter certeza do estado mental (dor) nos quais nos encontramos sem sabemos dos estados mentais de terceiros e do próprio mundo? $\mathrm{Na}$ sua forma mais clássica, proposta por Ryle (1949), o behaviorismo é a tese segunda a qual estados mentais se reduziriam a comportamentos ou a disposições comportamentais.

A mindreading reconhece que o comportamento observado desempenha um papel fundamental em qualquer concepção sobre outras mentes e dessa forma pressupõe, ainda que tacitamente uma uniformidade natural entre mentes humanas. Entretanto, ela recusa tanto o behaviorismo como a teoria da analogia: uniformidades entre mentes não deve nunca ser confundida com uma inferência analógica. Segundo o mindreading, adultos compreendem estados mentais de terceiros ao compreenderem como tais estados mentais se relacionam nomologicamente com os inputs sensoriais, outros estados mentais e os outputs comportamentais.

No quadro teórico da mindreading, duas teorias monopolizaram o debate interdisciplinar sobre a cognição de outras mentes por décadas, são elas a chamada teoria da teoria (TT) e a chamada teoria da simulação (TS). 2 A teoria da teoria (TT) sustenta, em linha gerais, que as relações nomológicas entre inputs ambientais, estados mentais e out-

\footnotetext{
${ }^{2}$ Conferir: CARRUTHERS 2015.
} 
puts comportamentais são representadas nas mentes dos intérpretes sob a forma de uma teoria sobre a mente de terceiros. $]^{3}$ A teoria da teoria (TT) concebe, assim, a mindreading como uma forma tácita ou explícita de raciocínio teórico em terceira pessoa. Entretanto, opiniões divergem sobre até que ponto a teoria da teoria seria efetivamente análoga realmente às teorias científicas. Os defensores da TT, no entanto, concordam que os leitores de mente (intérpretes) entendem as mentes de terceiros, aplicando leis da psicologia popular aos comportamentos.

A teoria da simulação (TS) rejeita a suposição de que a teoria da interpretação exija representações mentais de terceiros figurem na mente dos intérpretes. Ao invés disso, sugere-se que a nossa compreensão sobre a mente de terceiros tenha lugar mediante uma estratégia de simulação (em primeira pessoa) e projeção, ou seja, seria simulando ou produzindo estados mentais fictícios ou imaginários que teríamos acesso cognitivo aos estados mentais de terceiros para, em seguida, imputá-los ao outro como seus próprios estados genuínos..$^{4}$ Tais simulações seriam rotineiras e funcionariam exatamente como o raciocínio psicológico popular.

Contudo, a rejeição que representações mentais de leis psicológicas este- jam configuradas na mente de terceiros não leva a TS a negar o papel do raciocínio na compreensão de outras mentes. Este teria a forma peculiar de uma estratégia que ALVIN GOLDMAN denomina "gerar e testar" (GOLDMAN, 2006, p. 45). Nesses casos, formamse hipóteses sobre os estados mentais de terceiros que poderiam ter causado o comportamento observado, mas depois inicia-se o procedimento de simulação para testar a respectiva plausibilidade das hipóteses aventadas e, finalmente, atribui-se a terceiros aqueles estados mentais que se apresentam como a hipótese mais plausível para a explicação da conduta observada. É nesse sentido que ROBERT M. GORDON insiste na "importância metodológica do teste de hipóteses e da experimentação em simulação" que existe no coração da cognição social por simulação um tipo de raciocínio que ele denomina "raciocínio hipotético-prático" (GORDON, 1986, pp. 162-163). Como herdeiras da tradicional teoria da analogia, TT e ST assumem o clássico problema de outras mentes como legítimo e fornecem soluções distintas, embora aparentadas para o mesmo: teorização e simulação mentais. Dito isto, a cognição dos estados mentais de terceiros só seria possível mediante algum processo psicológico que nos levaria a tais

\footnotetext{
${ }^{3}$ Conferir BARON-COHEN, LESLIE FRITH 1985; GOPNIK MELZOFF 1997; GOPNIL WELLMAN 1995; NICHOLS STICH 2003. A meu juízo, é inegável que haja relações nomológicas das quais se valha o intérprete. O discutível é se o intérprete as representa sempre como uma teoria tácita ou explícita. Esse não me parece ser caso quando tratamos de estados mentais elementares.

${ }^{4}$ Conferir GOLDMAN 2005; GORDON 1986; HEAL 1986.
} 
estados mentais a partir da percepção direta do comportamento das pessoas. Entretanto, é nesse particular que tanto a TT quanto a TS não se coadunam adequadamente com os achados empíricos da psicologia do desenvolvimento. Segundo esses achados, mesmo bebês em fase pré-linguística compreendem as expressões faciais dos seus cuidadores, sem se utilizar, obviamente, de recursos teóricos como hipóteses (TT) em terceira pessoa nem tampouco de simulações em primeira pessoa. Foram esses achados que motivaram o surgimento da teoria da interação (TI) de base enativista: como os bebês compreendem os estados mentais dos seus cuidadores, tal compreensão só poderia ser fruto de uma percepção direita.

É importante salientar que TT e ST não negam que a percepção desempenhe um papel fundamental como um mecanismo básico que coleta informações salientes (como dados de expressões faciais, características comportamentais, etc.). Com efeito, essas abordagens insistem em que as informações perceptivas do comportamento corporal devem ser processadas por mecanismos cognitivos de ordem superior consagrados nas suas respectivas formas de mindreading, como teorizar ou simular, formular hipóteses etc. sem os quais seria impossível a cognição dos estados mentais de terceiros. A suposição é que apenas perceber o comportamento cor- poral de terceiros nunca é o mesmo do que entender seus estados mentais.

\section{TI}

Mas a abordagem que nos importa aqui é a chamada abordagem por vezes chamada de abordagem da "segunda pessoa", às vezes de "teoria da interação" (TI), outras de "modelo de percepção direta" (MPD), ou ainda simplesmente "percepção social direta" (PSD). Ela emerge diretamente como uma crítica à TT e à ST. Segundo Gallagher: "a teoria da teoria e a teoria da simulação assumem o problema das outras mentes", porque assumem explicitamente que "outras mentes estão ocultas pelo comportamento manifesto que podemos observar" (GALLAGHER, 2004, p. 209). A ideia aqui é que estados mentais de terceiros seriam "transparentes", por assim dizer, a terceiros.

Pelo que observamos na seção anterior, essa tese central encontra motivação não apenas na descrição fenomenológica da interação entre mentes incorporadas. Ela supostamente encontra apoio também nos achados empíricos da psicologia do desenvolvimento. A TI alega que o clássico problema filosófico de outras mentes não se coloca à luz dos achados da psicologia do desenvolvimento.5 Mas que achados são esses? Alguns estudiosos relatam que

\footnotetext{
${ }^{5}$ Conferir GALLAGHER 2004.
} 
bebês desfrutam de uma forma primitiva de compreensão social dos estados mentais dos seus cuidadores bem antes de serem capazes de formular qualquer teoria sobre a mente de terceiros ou de simulares em primeira pessoa estados mentais. O caso mais conhecido na literatura é um experimento levado a cabo por ED TRONICK e colegas (1978), o "experimento facial". Mãe e bebê estão inicialmente envolvidos em uma interação recíproca se "comunicando" mediante expressões faciais e gestos corporais. Mas a mando do condutor do experimento, a mãe deixa repentinamente de responder às expressões e gestos da criança. Inicialmente, o bebê manifesta desconfiança. Em seguida busca de todas as formas chamar a atenção da mãe. Não tendo êxito, a criança perde o interesse pela mãe. Por relevante que seja tal experimento, ele levanta mais questões do que traz respostas. Primeiro, estariam os bebês realmente percebendo os estados mentais dos seus cuidadores? Segundo, de quais estados mentais estamos tratando nesse experimento? Terceiro, o que significa dizer que os bebês "compreendem" os estados mentais dos seus cuidadores? Retomarei esse "experimento facial" mais a frente e o compararei com um experimento em muitos aspectos similar feitos com cães domésticos.

Mas isso não é tudo. Outros estudos empíricos sugerem que mesmo ontogeneticamente formas primárias e préteóricas de consciência sobre estados de terceiros continuam a desempenhar um papel central na cognição de terceiros por parte adultos. Mas o ponto que merece destaque aqui é o seguinte. Se a a TT e a TS estiverem corretas, ao menos nas suas linhas mestras, a coordenação corporal entre indivíduos nada mais é do que a consequência da cognição prévia de estados mentais de terceiros, mas não a condição para a cognição de tais estados. Um compreende a mente do outro através de uma teoria e, subsequentemente, esse processo "individualista desincorporado" torna possível a coordenação corporal com outros corpos de terceiros. Ora, é justamente essa suposição central do mindreading que a TI rejeita. Segundo HANNE DE JAEGHER (2009); EZEQUIEL DI PAOLO (2009) e SHAUN GALLAGHER (2012), os estudos sobre a interação de adultos revelariam serem os tais encontros face a face-uma sintonização automática de sorrisos e outros gestos faciais-a condição e não a consequência para a compreensão dos estados mentais de terceiros.

Além dos experimentos mencionados, a TI suscita inúmeras questões. A primeira questão é se há ou não algum aspecto oculto da mente de terceiros pelas suas condutas. Reiterando, segundo a TI, estados mentais de terceiros seriam "transparentes", por assim dizer, àqueles com interagem. Essa transparência eliminaria a necessidade teorizações (TT) ou simulações (TS). Trocando em miúdos: observando o comporta- 
mento manifesto de outras mentes com as quais interagimos socialmente como agentes incorporados, conheceríamos diretamente (percepção) os respectivos estados mentais expressos por tais comportamentos.

Com base na fenomenologia da cognição da mente de terceiros, Gallagher sustenta então que: "na maioria das situações intersubjetivas, temos um entendimento direto das intenções de outra pessoa, porque suas intenções são explicitamente expressas em suas ações incorporadas" (GALLAGHER, 2004, p. 224). A TI recomenda que removamos o problema de acesso da agenda. A ideia parece ser que, como nos encontros face a face, a experiência perceptiva nos apresenta imediatamente a mente do outro. Nesses casos não precisaríamos e não teríamos como ir além da experiência perceptiva para entender estados mentais de terceiros. Entretanto, é importante salientarmos que mesmo os proponentes da TI admitem que ocasionalmente lançamos mão de teorias quando a percepção direta é insuficiente. Aqui há uma distinção entre a cognição de estados mentais elementares e complexos. Na melhor das hipóteses, o que a TI propõe é que nos casos de cognição de estados mentais elementares não precisaríamos ir além da percepção social imediata das condutas para entendê-los.

Ora, mesmo quando consideramos apenas a cognição de estados mentais elementares de outras mentes, a TI não me parece a teoria mais plausível. E a razão se encontra paradoxalmente no próprio EDMUD HUSSERL (a quem Zahavi apela): a noção de alteridade. Se o eu e o outro somos dois, tem que haver "transcendência". Estados mentais de outras mentes transcendem, ao menos em parte, o que percebemos diretamente pela nossa interação social com seus corpos manifesta nas suas ações.

Ora, ao que tudo indica mesmo os proponentes da TI estão conscientes da necessidade de acomodar a transcendência na sua explicação sobre o conhecimento da mente de terceiros. Zahavi é explícito a respeito: "experimentamos o comportamento dos outros como expressão de estados mentais que transcendem o comportamento que os expressa. (...). A alteridade do outro se manifesta exatamente na e inacessibilidade evasiva" (ZAHAVI, 2011, pp. 3536). A TI reconhece que podemos perceber imediatamente a mente de terceiros apenas em um aspecto bastante limitado.

E o que dizer então da "natureza oculta" dos estados de terceiros? Ora, ela nada mais é do que um espantalho filosófico criado apenas com a intenção de motivar a TI. Nem JEAN HEAL (1995), nem ROBERT M. GORDON (1986), nem mesmo ALISON GOPNIK (1995) jamais negaram que tenhamos acesso imediato à mente de terceiros no caso específico das emoções e sensações mais simples. De acordo com Heal: "nada do que eu disse foi no sentido 
de descartar a ideia (de que possuiríamos acesso cognitivo imediato a estados mentais elementares); e a exploração de suas conexões com a simulação pode ser interessante" (HEAL, 1986, p. 50). ${ }^{6}$ E mesmo Gopnik, que é conhecido por sustentar que estados mentais de terceiros nada mais seriam do que entidades teoricamente postuladas, tem o cuidado ao observar:

Em termos puramente fenomenológicos, nossa percepção dos estados mentais nos outros é ... não menos imediata do que nossa percepção dos nossos próprios estados mentais. Vejo a fome do meu filho ou a decepção do meu amigo tão diretamente quanto a minha. (GOPNIK, 1995, p. 269)

Diante disso, sempre que ST e TT assumem que os estados mentais são postulados com base em teorizações e simulações, obviamente eles não estão tratando dos sentimentos e emoções mais básicos. Teorizações e simulações dizem respeito apenas a estados mentais complexos de outras mentes. Tratase, portanto, de um típico espantalho filosófico criado pela TI. Isso levanta uma questão fundamental: se até mesmo fenomenólogos reconhecem que a alteridade se manifesta na sua "inacessibili- dade evasiva" é constitutiva da distinção entre o eu e o outro, qual seria então a diferença real entre TI, por um lado, e TT ST, quando tratamos da cognição dos estados mentais elementares de terceiros (para além dos espantalhos)?

Mas retomemos "experimento facial" de Tronick e colegas (1978). O bebê e seus cuidadores estariam envolvidos em uma "interação recíproca", na qual haveria uma compreensão mútua com base em suas expressões faciais e gestos corporais. Ora, cães também reagem a emoções básicas dos seus donos e de outros cães. Um experimento foi realizado com 17 cães domésticos não treinados por imagens e sons que transmitissem expressões emocionais positivas ou negativas em humanos e cães (ALBUQUERQUE e colegas 2016). Os cães usados no teste não estavam familiarizados com o procedimento; evitando qualquer possibilidade de condicionamento. O som de vocalização que acompanha os rostos humanos também não era familiar. Por fim, os cães testados eram britânicos, mas a língua utilizada foi o Português para se evitar qualquer familiaridade com os sons a qual estavam habituados.

Os resultados, publicados recentemente no jornal Biology Letters da Royal Society, revelaram que os cães passam muito mais tempo olhando para as expressões faciais que correspondem ao estado emocional da vo-

\footnotetext{
${ }^{6}$ Gordon afirma algo semelhante em GORDON, 1986, p. 169.
} 
calização, tanto para humanos quanto para caninos. Quando os cães ouviam sons positivos, eles olhavam por mais tempo para rostos positivos, tanto humanos quanto caninos. E quando ouviam sons negativos, olhavam por mais tempo para rostos negativos e raivosos. O estudo mostra que os cães podem integrar duas fontes diferentes de informações sensoriais em uma percepção de emoção em humanos e cães. Os pesquisadores acreditam que a capacidade de decodificar estados emocionais elementares a partir de condutas seria inerente aos cães como a todas as espécies sociais como nós humanos.

$\mathrm{O}$ que devemos concluir que desse experimento? Que os estados mentais dos cuidadores seriam transparentes aos cães (como seriam aos bebês)? Cães "compreenderiam" imediatamente os estados mentais de humanos quando com eles interagem? Creio que de longe a conclusão mais plausível seja que tanto bebês como cães possuem conceitos muito rudimentares de emoções positivas e negativas, ou seja, contentamento e descontentamento. E isso é tudo do que precisamos para entender as tais interações face a face entre bebês e seus cuidadores.

Mas o ponto crucial dessa seção é a tese de Merleau-Ponty (MERLEAUPONTY, 2002, p. XIII) segundo a qual possuiríamos um acesso imediato a mente de terceiros, franqueado pelas suas "ações incorporadas". A despeito do seu ar de novidade, a ideia nada tem de novo. A rigor, na primeira metade do século passado todos os filósofos que reconheceram a inviabilidade do clássico modelo da inferência analógica acabaram por "flertar", por assim dizer, com alguma forma de behaviorismo. E a razão é bastante óbvia: como a inferência analógica é "problemática" (para se dizer o mínimo), o resultado indesejável seria o ceticismo relativo a outras mentes e o solipsismo.

$\mathrm{Na}$ sua forma mais extremada, o behaviorismo é a tese segunda a qual enunciados sobre estados mentais seriam traduzíveis em enunciados sobre comportamentos e disposições de comportamentos. Entretanto na sua forma mais branda, postula-se apenas uma conexão conceitual qualquer entre uns e outros e é exatamente isso que observamos na filosofia da mente de LUDWIG WITTGENSTEIN77. Segundo Wittgenstein, estados mentais e comportamentos típicos se conectariam semanticamente com base no que o filósofo austríaco denomina "critério", ou seja, uma evidência conceitual (embora nem indutiva nem dedutiva). A percepção da conduta padrão de dor seria um critério (ainda que falível) de que uma pessoa tem dor. Por quê? Porque antes de correlacionar indutivamente a palavra dor ao comportamento típico de dor com base na observação repetida

\footnotetext{
${ }^{7}$ Conferir CHARLES S. CHIHARA e JERRY FODOR 1965.
} 
do padrão de comportamento de dor, simplesmente apreendi o significado da palavra "dor" com base nesse comportamento padrão de dor.

Embora a fenomenologia MerleauPonty não seja uma reflexão sobre a linguagem comum, tal como a implementada por Wittgenstein, as semelhanças são óbvias:

Não vejo a raiva ou uma atitude ameaçadora como um fato psíquico oculto por trás do gesto, leio a raiva nele. $\mathrm{O}$ gesto não me faz pensar em raiva; é a própria raiva. No entanto, o significado do gesto não é percebido como a cor do tapete, por exemplo, é percebida. Se isso me foi dado como algo, não está claro por que minha compreensão dos gestos deve, em grande parte, limitar-se aos humanos (MERLEAU-PONTY, 2002 , p. 214, grifos meus).

Segundo Merleau-Ponty, o significado do gesto não estaria associado ao respectivo estado mental de forma indutiva (tal como a cor do tapete). Por isso, afirma o filósofo francês, "lemos" a ira na ação incorporada ou, pior ainda, que o gesto de ira seria a própria raiva nada tem de novo. Os argumentos contra o behaviorismo são tão conhecidos que nem são dignos de nota. Limito-me a assinalar aqui que a TI se apresentada como um "revival" do antigo behaviorismo.

\section{A Percepção Inteligente (Smart Per- ception)}

Para fins de argumentação, assumo a tese fundamental segundo a qual a cognição dos estados mentais elementares de outras mentes tem a forma de uma percepção direta e não de uma inferência. Mas o que vem a ser uma percepção direta? Prima facie, a TI rejeita o que Merleau-Ponty denominava de "intelectualismo," ou seja, a suposição de que a cognição da mente de outras mentes dependeria de interpretações, reflexões e juízos, teorizações e simulações. Segundo Merleau-Ponty:

Não entendo os gestos dos outros por algum ato de interpretação intelectual; a comunicação entre consciências não se baseia no significado comum de suas respectivas experiências, pois é igualmente a base desse significado. (MERLEAUPONTY, 2002, p. 216)

Mas aqui surge o primeiro problema. Segundo Gallagher, a percepção direta exigiria um certo grau de sofisticação ou, nas suas palavras: "inteligência" (Smartness). Gallagher afirma que uma percepção direta de emoções deve ser inteligente o suficiente para compreender o significado dos estados emocionais: 
Quando vejo a ação ou o gesto do outro, vejo (percebo imediatamente) o significado da ação ou gesto. Vejo a alegria ou a raiva, ou a intenção no rosto ou na postura ou no gesto ou ação do outro. (GALLAGHER, 2008, p. 542)

Gallagher apresenta dois exemplos contrastantes. Um de uma percepção "não-tão-inteligente" do seu carro e o outro do que seria uma percepção dita "inteligente" do mesmo carro. No caso da "percepção não tão inteligente", afirma Gallagher: "vejo uma certa massa vermelha irreconhecível com uma forma específica bem na minha frente" (GALLAGHER, 2008, p. 536). A isso ele acrescenta que tal "massa vermelha sem sentido" deve então ser interpretada em alguns outros passos cognitivos "não visuais e não perceptivos que vão além da própria percepção" (GALLAGHER, 2008, p. 536).

No caso da percepção inteligente, ele simplesmente vê a massa vermelha como um carro e, mais especificamente, ele vê a massa vermelha como o seu carro. A forma e a cor específicas da coisa ainda são vistas, mas são agora como aspectos de algo que é "reconhecível como sendo o meu carro" (GALLAGHER, 2008, p. 536). A percepção "inteligente" deve ser sensível ao tipo de propriedade do objeto: a propriedade de ser um carro, não apenas uma coisa vermelha. Também deve ser sensível a uma propriedade relacional desse objeto: a propriedade de ser o carro de Gallagher.

Aqui já podemos observar uma grave incongruência. Por um lado, nos é dito que percepção direta de outras mentes é "anti-intelectualista", ou seja, não se baseia em reflexões, juízos e inferências. Ademais, segundo o modelo teórico proposto, a percepção direta deveria ser fundamental, ou seja, algo que crianças pequenas seriam capazes de realizar mesmo sendo ainda incapazes de julgar e conceituar de forma sofisticada o que lhes aparece. Mas se por um lado, nos é dito que a percepção inteligente deveria ser "sensível" aos tipos e às propriedades relacionais das coisas vistas. Por outro, a ideia de uma percepção inteligente parece exigir justamente aquilo que o anti-intectualismo exclui: conceituações sofisticadas que dependem de interpretações, reflexões e juízos (intelectualismo).

Com efeito, dos exemplos fornecidos por Gallagher emerge claramente que a oposição entre percepção "não-tãointeligente" e percepção "inteligente" não passa de uma oposição entre o conhecimento conceitual rudimentar do carro e o conhecimento conceitual sofisticado do que "significa" ver um carro. Pois, no caso da percepção "não tão inteligente," o observador não possui os recursos conceituais sofisticados para especificar que o que está vendo como um carro, muito menos que está vendo 
o próprio carro. Mutatis mutandis, para perceber diretamente a raiva, a tristeza ou a alegria no rosto dos seus cuidadores, os bebês já deveriam estar equipados com sofisticados conceitos de raiva, tristeza e alegria. A menos que assumamos a tese inativista de CHALERS DARWIN, hoje inteiramente descreditada, a posição de Gallagher é insustentável. Reiterando o que dissemos, o mais plausível é supor que bebês apreendam desde de cedo a conceituar de forma bastante rudimentar os estados os seus cuidadores como emoções de contentamento e de descontentamento.

A inconsistência na posição de Gallagher pode ser formulada sob a forma de um dilema fundamental: ou bem os defensores de TI assumem que as percepções diretas "não são inteligentes" ou devem abandonar a ideia o anti-intelectualismo que dizem herdar de Merleau-Ponty. Caso tenhamos que abandonar o anti-intelectualismo, pergunta-se então: qual seria então a vantagem da TI sobre TT e ST?

\section{Percepção Epistêmica}

Em razão da rejeição da mindreading, a TI supõe uma forma de acesso direto a outras mentes. Ao entrar em contato direto com os comportamentos dos adultos, a criança não representa os estados mentais do adulto, mas entra em contato direto (acquaintance) com esses próprios estados mentais. Versões dessa concepção da experiência perceptiva eram populares em Oxford do início do século XX (Russell). Entretanto, os trabalhos recentes de JOHN CAMPBELL, CHARLES TRAVIS, JOHN JONSTON, BILL BREWER, WILLIAM FISH E MGM MARTIN trouxeram a proposta de volta à discussão. Travis denomina tal concepção da percepção de "realismo ingênuo". Prefiro, no entanto a denominação proposta por Campbell 2002: concepção relacional ("relational view") da percepção.

A essa concepção se opõe à chamada concepção do conteúdo ("content view") da percepção (sigo mais uma vez a denominação de Campbell). Perceber não se resume a uma relação de contato direto com particulares. Perceber significa "apresentar o mundo de uma determinada forma". Quando vejo uma mariposa em uma árvore, apresento o mundo de uma forma bem específica. Isso é o que hoje se denomina de conteúdo representacional. Mas como não estamos lidando com uma atitude proposicional, prefiro dizer que tal conteúdo exprime condições de veridicidade (e não condições de verdade). Não obstante, como no caso das crenças, a direção de ajuste é no sentido da mente para o mundo, ou seja, para ser "verídico" o conteúdo representacional deve se ajustar ou corresponder à forma ou à maneira como o mundo efetivamente se comporta. Assim, quando há uma correspondência entre a maneira como nossas experiências perceptivas 
apresentam o mundo (seu conteúdo) e a maneira como este se comporta, o conteúdo é verídico; caso contrário, o conteúdo não seria verídico. Assim, quando vejo uma mariposa em uma árvore, o conteúdo da minha percepção é verídico se houver uma mariposa no local e tempo específico para o qual estou olhando, causando o meu estado perceptual da maneira usual e de forma apropriada.

No entanto, Gallagher se dá conta que a percepção direta social de outras mentes além de "inteligente" deveria ser também "epistêmica". Isso significa que a percepção de uma emoção, como a ira, por exemplo, envolve perceber que estamos diante de um gesto de ira ou que a pessoa que está irada. Assim, a suposta relação direta de contato perceptivo com a instanciação de ira não é ainda suficiente para TI. E a razão me parece a seguinte: eu posso perceber a instanciação de ira sem me aperceber de que a pessoa está irada. Assim, a despeito de dizermos que percebemos particulares concretos, perceber a alegria ou a raiva no rosto de Jackie ou Jeffrey não é simplesmente uma questão de perceber algo, mas de perceber fatos: "perceber que Jackie está com raiva e Jeffrey é a alegria F" (GALLAGHER, 2012, p. 188, ênfase adicionada).

Ora, se por um lado o interacionismo de Gallagher apela inequivocamente à concepção relacional da percepção, por outro, ele se desvia da mesma. Basta conferirmos o que Travis diz a respeito: "Se Pia viu que João estava andando", "ver" aí nada tem mais a ver com o sentido perceptual de "ver" (GALLAGHER, 2013, p. 838). O ponto se aplica igualmente à formulação em termos de "ver S como sendo F", prossegue Travis: "a percepção, como tal, simplesmente coloca o nosso entorno à vista; nos dá consciência dele. Não há compromisso com a suposição de serem de um jeito ou de outro" (TRAVIS, 2004 , p. 65). De acordo com a visão relacional, as percepções seriam "cegas" e a razão para isso é muito clara: elas não seriam proposicionais.

Isto posto, além da percepção "inteligente" de Gallagher exigir recursos conceituais sofisticados, a percepção "epistêmica" de Gallagher exige conteúdos proposicionais: ver x é significa ver que $x$ é $F$. Usando a terminologia de Dretske, a percepção direta inteligente e epistêmica não é uma "percepção" em sentido usual (de objetos), mas antes a percepção de fatos (fact-awareness). Ora, mas isso pressupõe exatamente o que Gallagher dizia rejeitar: o representacionismo. E por quê? Simplesmente porque se ver $x$ significa ver que $x$ é $\mathrm{F}$, posso sempre me enganar quanto a ser $\mathrm{F}$ a propriedades que $\mathrm{x}$ instancia. Onde se a percepção epistêmica possui um conteúdo proposicional sempre há a possiblidade de erros. Para perceber epistemicamente a expressão facial irada de Jackie, tenho que representar a proposição de que Jackie esteja irada. Esse conteúdo proposicional sobre o es- 
tado de Jackie será verídico caso Jackie efetivamente estiver com raiva; inverídico, caso Jackie não estiver com raiva.

Imaginemos, agora, que Rosemary tenha um bebê e que ela ora sorria para ele, ora franza a sua testa exprimindo seu descontentamento. Ora, para entender que a sua mãe está ora alegre ora descontente ou irada, bebê de Rosemary precisa, antes de mais de nada compreender as expressões faciais de alegre e de descontente, caso contrário, a sua percepção ainda que direta não seria "tão-inteligente". Mas para isso, o Bebê necessita reconhecer expressões faciais de alegria e de descontentamento por meio de conceitos mais ou menos sofisticados que um bebê não parece possuir. Nesse particular o interacionismo de Gallagher está claramente comprometido com uma forma de intelectualismo. Mas isso não é tudo. Para perceber epistemicamente que a sua mãe ora está alegre e ora está contente, o bebê de Rosemary necessita perceber que é o caso que Rosemary está alegre ou descontente. O interacionismo de Gallagher está tacitamente comprometido com o representacionismo.

Mas essa pressuposição nos leva a uma reversão da ordem de explicação proposta pelo interacionismo de Gallagher. Ao invés de mostrar que relação de contato epistêmico com a expressão facial alegre da mãe e, a fortiori, que a ação de um "agente incorporado" precede quaisquer formas de conteúdo representacionais, o que observamos é justamente o contrário: são os conteúdos representacionais que tornam possível a interação social entre o bebê e Rosemary.

\section{Enactivismo e os Corpos Estendidos}

Mas como observei, as raízes da TI são as teses do chamado enactivismo. 8 Ora, como o enactivismo remonta a Merleau-Ponty, nada mais natural do que os defensores de TI também sigam o filósofo francês. O foco da primeira fase do enactivismo não era o representacionismo (content view) na filosofia da percepção, mas o cognitivismo na filosofia da ciência cognitiva. Segundo FRANCISCO VARELA e colegas (1991), o enactivismo pode ser caracterizado pela rejeição das seguintes teses:

\section{1) O mundo é "dado" (pregiven).}

2) Nossa cognição é deste mundo.

3) A maneira pela qual conhecemos esse mundo pré-determinado é representar suas características e de-

\footnotetext{
${ }^{8}$ Foram Valera e seus colegas que introduziram a palavra "enactivismo" em 1991. No prefácio do compêndio eles dizem: "Gostamos de considerar nossa jornada neste livro como uma continuação moderna de um programa de pesquisa fundado há uma geração pelos franceses. filósofo, Maurice Merleau-Ponty. Por continuação, não queremos dizer uma consideração acadêmica do pensamento de Merleau-Ponty no contexto da ciência cognitiva contemporânea. Queremos dizer, antes, que os escritos de Merleau-Ponty inspiraram e guiaram nossa orientação aqui". (VARELA e colegas, 1991, p. XV)
} 
pois agir com base nessas representações." (VARELA e colegas, 1991, p. 135)

A primeira tese "cognitivista" nada mais é a expressão do realismo ingênuo que o próprio Gallagher assume. $\mathrm{O}$ mundo a ser conhecido é independente da nossa mente, das nossas interações com o mesmo e de qualquer construção conceitual que dele façamos. A segunda tese "cognitivista" consiste na suposição de que a nossa cognição diz respeito a esse mundo como algo dado independente de nós. Finalmente, a terceira tese "cognitivista" consiste na afirmação de que a experiência perceptiva depende de estados internos que "representam" as características desse mundo dado independente de nós. Por exemplo, a tarefa da visão, de acordo com o "cognitivista", depende de uma representação mental interna do layout real do mundo tridimensional exterior. Tal representação, sendo verídica, seria necessária para que o sujeito possa agir e interagir com os seus coespecíficos de forma apropriada.

Em oposição à primeira tese cognitivista (o realismo ingênuo), o enactivismo afirma que o mundo a ser conhecido não é pré-determinado - "o mundo de um ser cognitivo não é um domínio externo pré-especificado" como EVA THOMPSON coloca (THOMPSON, 2007, p. 13). A crítica à segunda tese é uma decorrência da primeira. Segundo o enactivismo, a cognição não é "sobre" um mundo independente das nossas mentes e das nossas ações. Pelo contrário, trata-se de um mundo cujas próprias características emergem da interação entre o sujeito cognoscente e o seu ambiente. Segundo Varela e colegas, mundo e sujeito cognoscente "se especificam mutuamente" (VARELA e colegas, 1991, p. 172). A fonte de inspiração da crítica ao cognitivismo é Merleau-Ponty:

O filósofo tenta conceber o mundo, os outros e a si mesmo e suas inter-relações. Mas o ego meditativo, o 'espectador imparcial' (Zuschauer desinteressado) não redescobre uma racionalidade já dada, eles 'se estabelecem', e a estabelecem, por um ato de iniciativa que não tem garantia de ser, sua justificação repousando inteiramente no poder efetivo que nos confere de levar nossa própria história sobre nós mesmos. (MERLEAUPONTY, 2002, p. XII, ênfase adicionada)

Na passagem supracitada, MerleauPonty faz jus à sua condição de filósofo francês. Em que sentido nem o mundo nem o sujeito seriam "dados"? Não haveria uma realidade impendentemente de ser percebida e conhecida? Da mesma forma, como sujeitos cognoscentes não possuiríamos uma natureza biológica dada, como homo sapi- 
ens, sapiens (ainda que tal natureza seja "plástica)? Mas o que causa ainda mais espécie é a afirmação de que mundo e sujeito cognoscente "se especificam mutuamente" que Varela e colegas atribuem a Merleau-Ponty.

Por último, a percepção não seria uma representação mental interna do mundo que posteriormente guiaria a nossa ação. Essa suposição cognitivista incorreria em dois erros, segundo os enativistas. Primeiro, ação e percepção não seriam atividades distintas tal como o cognitivista supõe. A cognição/percepção é uma forma de "ação incorporada" (embodied) em um ambiente, nas palavras de Thompson seria "o exercício de conhecimentos hábeis na ação situada e incorporada" (THOMPSON, 2007, p. 13). Em segundo lugar, cognitivistas "tomam erroneamente a representação como a sua noção central" (VARELA e colegas, 1991 , p. 172) quando, a bem da verdade, os sistemas cognitivos não operam com representações internas ao produzirem cognições.

Mas deixem-me, em primeiro lugar, focar na questão da representação. Como JOHN SEARLE observava: "provavelmente não existe um termo ambíguo na história da filosofia do que 'representação'” (SEARLE, 1983, p. 11). Com efeito, filósofos, mas também cientistas cognitivos, têm em mente as coisas mais diversas quando se põem a falar de "representação". Por exemplo, na filosofia moderna dos séculos
XVII e XVIII, supunha-se que as experiências perceptivas representavam o mundo mediante imagens mentais dos objetos reais. Os filósofos daqueles séculos (com a exceção louvável de IMMANUEL KANT) tomavam essa "imagem mental" ou "experiência interior" como um intermediário epistemológico entre o sujeito e o mundo exterior. Para conhecermos objetos exteriores a nós, deveríamos primeiro perceber introspectivamente imagens mentais que fossem semelhantes aos mesmos (como falar aqui se semelhança se não teríamos acesso à próprias coisas). Depois deveríamos averiguar se tais objetos seriam a causa mais plausível da ocorrência de tais imagens. A Refutação do idealismo de Kant é a refutação cabal desse modelo de acesso ao exterior.

Desafortunadamente, é nesse sentido pré-kantiano que a noção de "representação" está sendo tomada pelos enativistas, ou seja, como a "re-apresentação de um mundo pré-determinado" (VARELA e colegas, 1991, p. 148). "Representação" seria um substituto da realidade exterior no interior da mente humana, segundo Descartes o modo "objetivo" ou intencional pelo qual a coisa se apresenta ao intelecto. É exatamente a mesma ideia que Varela e seus colegas assumem:

Há três suposições fundamentais. A primeira é que habitamos um mundo com propriedades de particulares tais como 
comprimento, cor, movimento, som etc. A segunda é que captamos ou recuperamos essas propriedades, representando-as internamente. A terceira é que existe um "nós" subjetivo separado que faz tais coisas. Essas três suposições representam um compromisso forte, muitas vezes tácito e inquestionável com o realismo ou o objetivismo/subjetivismo sobre o modo como o mundo é, o que somos e como chegamos a conhecer o mundo. (VARELA e colegas, 1991, p. 9)

No entanto, para avaliar de maneira adequada o debate sobre a terceira tese cognitivista sem apelarmos a "espantalhos," devemos tomar a "representação" da forma como a apresentamos na seção passada. A ideia aqui não é a tradicional de um substituto da realidade exterior que "re-apresenta tal realidade no interior da mente." A ideia aqui é a de que toda cognição envolve condições de satisfação. Quando acredito que temos um dia ensolarado, apresento o mundo de uma certa maneira, a saber, a maneira expressa pela proposição que o dia está ensolarado. O conteúdo dessa crença é verdadeiro se tivermos um dia ensolarado; falso caso o dia não esteja ensolarado. No caso das crenças, a direção do ajuste é da mente para o mundo: a crença só é verdadeira em virtude da maneira como o mundo se comporta.
Para evitarmos o mal-entendido, talvez devêssemos falar de apresentações ao invés de representações. O que está na mente não é uma imagem que se assemelha à coisa exterior ou a apresenta ao intelecto, mas apenas um "veículo" do que é apresentado.

À essa noção Varela e colegas não parecem se opor:

Esse sentido de representação é fraco porque não apresenta compromissos epistemológicos ou ontológicos fortes. Portanto, (...) é perfeitamente aceitável pensar em uma afirmação como representando algum conjunto de condições sem fazer suposições adicionais sobre se a linguagem como um todo funciona dessa maneira ou se realmente há fatos no mundo separados da linguagem que podem ser reapresentados pelo frases da língua. (VARELA e colegas, 1991, p. 135)

No entanto, a chamada "concepção de conteúdo" (content view) nada tem de trivial nem do ponto de vista ontológico nem do ponto de vista epistemológico. Primeiro, os críticos (relacionistas) sustentam que, de acordo com a concepção de conteúdo, "objetos reais percebidos" não constituem metafisicamente os respectivos estados perceptivos. Isto posto, do ponto de vista epistemológico, os relacionistas sustentam 
que a percepção deveria ser uma relação genuína de contato cognitivo entre o percebedor e o objeto percebido. Finalmente, é importante salientar que todos os princípios do cognitivismo acima listados (com os seus compromissos ontológicos e epistemológicos) estão em vigor na concepção de conteúdo da experiência perceptual: "(1) o mundo está "dado"; (2) nossa cognição é sobre este mundo dado e (3) a maneira pela qual conhecemos esse mundo dado é representando particulares e suas propriedades para apenas então podermos agir com base nessas representações" (VARELA e colegas, 1991, p. 135). O que, com efeito, trivializa o debate é a suposição de que "representar" é "reapresentar" o mundo dado dentro da mente. Isso torna o debate sem sentido. Se o enactivismo estiver correto, as experiências perceptivas não podem ter conteúdo (condições de veridicidade).

No entanto, enativistas mais recentes apoiam a "concepção relacional" contemporânea da experiência perceptiva. Como observamos na seção passada, essa relação é concebida como uma relação de contato epistêmico direto com as coisas (knowledge by acquaintance). É importante se observar, contudo, que ao assumir a "concepção relacional", os enativistas não podem mais rejeitar os três princípios do cognitivismo. Primeiro, o realismo ingênuo é incompatível com o idealismo ingênuo expresso pela rejeição de (1) de que o mundo está "dado". Pela mesma razão, o realismo ingênuo também é incompatível com a negação (2) de que a nossa cognição seja desse mesmo mundo dado. Finalmente, o realismo ingênuo é incompatível com a suposição mundo e sujeito surjam de uma especificação mútua (VARELA e colegas, 1991, p. 172).

Acredito que essa seja a razão pela qual Gallagher e MATT BOWER (GALLAGHER E BOWER, 2014, p. 233) distingam três períodos de enactivismo: $\mathrm{o}$ enactivismo "precoce" de Varela e colegas (que remonta a Merleau-Ponty), o enactivismo "intermediário", representado por ALVA NOË e J. KEVIN O'REGAN, e o enactivismo "mais recente" e radical de ambos autores além de DANIEL HUTTO e ERIK MYIN. A questão premente é: todos eles rejeitam a chamada "concepção de conteúdo?" Essa é uma questão de difícil resposta. Varela e seus colegas não parecem rejeitar concepção do conteúdo, na medida em que supõe, erroneamente, que ela não tem compromissos ontológicos ou epistemológicos. Noë oscila. Em 2004, ele afirmava que "a sensação perceptiva constitui experiência - ou seja, possui conteúdo representacional genuíno" (NOË, 2004, p. 16). No entanto, um ano depois, ele passa a dizer que: "a percepção não é representativa no sentido de que as percepções ... não são sobre o mundo, são episódios de contato com o mundo" (NÖ̈, 2005, p. 226).

Hutto e Myin assumem uma posição clara contrariamente à concepção do conteúdo. Eles defendem uma versão 
"radicalizada" - que eles chamam de "REC" do enactivismo. REC é uma concepção sobre cognição humana (e animal) e sobre a mente em geral. O subtítulo de Hutto e Myin (2013) - "Mentes básicas sem conteúdo" - já indica claramente que mentes e cognição 'básicas' não envolvem nenhuma forma de conteúdo. No entanto, eles não deixam claro porque rejeitam a concepção do conteúdo. No prefácio de próprio livro (2013), por exemplo, eles se limitam a dizer que "pode haver (...) experiência perceptiva sem conteúdo" (HUTTO E MYRIN, 2013, p. 6). Mais à frente dizem que: "é possível que mesmo formas sofisticadas de percepção visual humana não sejam essencialmente representativas" (HUTTO E MYRIN, 2013, p. 82), sugerindo assim elas poderiam possuir um conteúdo, sendo esse, no entanto, não é essencial.

Mas deixemos de lado a controversa noção de "representação" e examinemos mais de perto o que Thompson seus colegas na ciência cognitiva têm em mente (tácita ou explicitamente). $\mathrm{O}$ que eles sugerem é que o "know-how" poderia substituir o "saber que algo é o caso” (THOMPSON, 2007, p. 13), o conhecimento proposicional. A ideia (incorporada pelo enativistas) não traz de novo. Ela remonta ao velho behaviorismo GILBERT RYLE (1949). Ora, JASON STANLEY e TIMOTHY WILLIAMSON (2001) desconstroem por completo esse credo behaviorista com uma das análises semânticas mais finas que conheço das orações da forma "knowwh" (-quem, -onde, quando, o que). Segundo Stanley e Williamson "saber como" (know-how) é uma forma de "know-wh" e que este é em geral é uma forma de saber proposicional: o que se sabe quando se sabe ("know-wh") é uma proposição verdadeira. "Knowhow" é um caso de saber proposicional.

Deixemos de lado a fina e sofisticada refutação de Stanley e Williamson, e consideremos uma história real. JOÃO CARLOS MARTINS é um conhecido pianista brasileiro cuja vida foi marcada por uma série de tragédias pessoas que pouco a pouco foram impossibilitando a sua carreira como pianista. Logo aos cinco anos, foi submetido a uma cirurgia de retirada de um tumor benigno no pescoço. Uma operação malsucedida o deixou com uma fístula na pele por onde vazava o alimento sempre que comia. Para uma criança de cinco anos, a música foi a sua salvação. Entretanto, aos 8 anos, João Carlos Martins passou pela segunda cirurgia e ficou curado da sua enfermidade infantil, ganhou confiança e se dedicou ainda mais ao piano. Venceu um concurso para executar obras de JOHAN SEBASTIAN BACH no qual o pai o havia inscrito e se sagrou como um virtuoso da execução da obra de Bach. Com 11 anos, iniciou seus estudos com um dos grandes mestres da época, o russo JOSÉ KLIASS, e venceu o concurso da Sociedade Brito de São Petersburgo. Aos 13 anos, iniciou sua carreira de concertista no Brasil e, aos 18, 
no exterior. Com 20 poucos anos, João Carlos Martins era um pianista aclamados pelo mundo, sendo considerado por muitos especialistas como um dos maiores interpretes de Bach da sua geração. O hoje maestro já havia se apresentado no famoso Carnegie Hall, patrocinado por ELEANOR ROOSEVELT, que lhe abriu as portas dos EUA.

Ele gravou a obra completa para teclado de Bach e realizou, com o pianista ARTHUR MOREIRA LIMA, o encontro entre os prelúdios para teclas do alemão e os prelúdios para piano do polonês FREDERIC CHOPIN. Inaugurou o memorial GLENN GOULD em Toronto, quando se viu privado de realizar o que amava. Em 1965, Martins vivia em Nova Iorque, quando foi convidado para integrar o time profissional da Portuguesa em um jogo treino realizado no Central Park. Toda felicidade por jogar pelo seu time de coração, se transformou em desespero em apenas um segundo. Uma jogada isolada, um lance tido como normal, uma queda aparentemente boba, uma perfuração na altura do cotovelo que atingiu o nervo ulnar. Esse "pequeno acidente" provocou atrofia em três dedos de sua mão, impossibilitando-o de tocar por um ano inteiro. A recuperação foi longa e complicada, fazendo com que o maestro tocasse com dificuldade até os 30 anos. Mas esse foi apenas um dos percalços que João Carlos teve que superar durante sua trajetória. Após longos períodos de fisioterapia, o pianista (hoje maestro) voltou aos palcos e, mesmo com a dificuldade, as críticas foram as melhores possíveis. No entanto, novamente foi impossibilitado de tocar o piano devido à distúrbios osteomusculares relacionados aos trabalhos (Dort).

Mesmo com mais uma adversidade, o pianista não desistiu de sua carreira, adaptando-se às restrições que o problema lhe causava, retomou sua carreira, voltando a tocar de 1979 a 1985. Realizou 10 gravações de Bach, conseguindo concluir o restante de todas as gravações da obra do famoso compositor alemão. Entretanto, em 1995, mais uma vez João Carlos Martins foi derrubado pelo destino e mais uma vez se recusou a ficar no chão. Durante um assalto na cidade de Sófia na Bulgária, o pianista foi golpeado na cabeça com uma barra de ferro, vítima de um assalto. A pancada comprometeu seriamente o seu braço direito. Depois de alguns processos cirúrgicos, e o álbum último com as duas mãos, foi necessário cortar a ligação entre o cérebro e o membro, comprometendo seus movimentos para sempre.

$\mathrm{O}$ que foi que o feito pelo pianista depois disso? Gravou o álbum "Só para Mão Esquerda". Todas as composições contidas nele foram de PAUL WITTGENSTEIN, que perdeu o mesmo membro na Segunda Guerra Mundial. Sua ideia era gravar 8 álbuns com essa temática, porém, foi descoberto um tumor em sua mão esquerda. Entretanto, aos ouviu do seu médico que nunca 
mais tocaria piano. Nesse momento, morre um pianista e nasce um maestro. No dia seguinte, João Carlos se inscreveu em aula de regência. Por causa da dificuldade de coordenação dos movimentos de seus dedos e a incapacidade de segurar a batuta e virar as páginas das partituras dos concertos na velocidade necessária, teve que memorizar nota por nota.

A pergunta interessante é a seguinte: Diríamos que quando João Carlos Martins ouviu do seu médico que nunca mais tocaria piano, ele simplesmente deixou de saber como se toca o piano? João Martins sabia tocar piano com grande maestria e agora não sabe mais? Ele teria se esquecido de como se faz (know-how) para executar as obras de Bach ao piano? Isso me soa completamente contraintuitivo: tudo indica que ele ainda hoje João Carlos Martins sabe e, muito bem, como tocar piano, a despeito das inúmeras tragédias pessoais que tenham o tornado inepto para tocar o instrumento.

Inúmeros experimentos conduzidos pelo grande cientista MIGUEL NICOLELIS assinalam que mesmo debilitado fisicamente, o córtex sensório-motor é capaz de mover diferentes corpos, robôs e até avatares como se fossem seus. A tecnologia atual ainda é incipiente, mas da mesma forma como Nicolelis dos EUA fez um paraplégico dar o pontapé inicial da copa do mundo realizada no Brasil no Maracanã, não há porque duvidarmos que no futuro pessoas como
João Carlos Martins possam voltar a tocar piano com a mesma maestria de sempre mediante avatares, utilizando seu córtex sensório-motor, sua memória, e demais sistemas corticais complexos.

Ademais, se João Carlos Marins não soubesse mais como tocar piano (knowhow to play), seu lamento teria a forma: "ah se eu ainda soubesse tocar piano?" Mas obviamente esse não é o seu lamento, mas antes: "ah, se eu ainda $p u$ desse tocar o Cravo bem temperado de Bach?" Ah, se eu ainda pudesse executar as Poloneses de Chopin?" "Ah, se eu ainda pudesse tocar as sonatas para piano solo de Beethoven!" João Carlos Martins não deixo de saber como (know-how) tocar piano! João Carlos Martins simplesmente não pode mais fazer o que ele ainda sabe fazer. Casos como o do João Carlos Martins são raros na história da música. Mas muito frequentemente quando um grande virtuose não de vê mais capaz de tocar com a mesma maestria, ele se torna um exímio professor do instrumento. Isso é mais um indicativo que, idoso, o instrumentista nunca deixa de saber como (knowhow) tocar. Ele apenas não consegue mais tocar como quando jovem por limitações impostas pela idade. Além de refutar cabalmente as análises behavioristas da cognição como know-how, exemplos como o do João Carlos Martins indicam que saber tocar piano não é uma atividade das mãos biológicas, mas das mãos enquanto representadas 
pelo cérebro.

Mas por que diabos a percepção usual dependeria da tal "incorporação"? A defesa proposta por MerleauPonty se apoia nas "constantes perceptuais". Constantes perceptuais são capacidades perceptuais para representar sistematicamente algum dado particular ou atributo como aquele mesmo particular ou mesmo atributo sob variações significativas no registro da estimulação proximal. Em uma constância perceptual, um sistema perceptivo pode representar algum dado aspecto do ambiente físico como aquele aspecto de diferentes perspectivas perceptivas, produzido por diferentes estímulos próximos. Por exemplo, a constância do formato é a capacidade de perceber uma mesma determinada forma sob vários estímulos e condições de perspectiva. Um padrão quadrado pode ser visto como quadrado, seja visto de frente ou em ângulo. A constância de localização é uma capacidade de representar particulares percebidos como a uma dada distância e direção, sob vários tipos de estimulação derivados de vários tipos de particulares percebidos. Os sistemas de sonar de morcegos, baleias e golfinhos e os sistemas visuais de vários animais podem localizar objetos, mesmo se os objetos em um determinado lo- cal mudarem muitas de suas propriedades de modo a produzir estimulação proximal muito diferente. Constante da luminosidade é a capacidade de representar um dado padrão de cor como a mesma sob várias condições de estímulo, incluindo diferentes iluminações.

Merleau-Ponty está coberto de razões quando sustenta que não alcançamos essas constâncias perceptuais por reflexão ou julgamentos. Criticando o suposto intelectualismo de Kant, ele afirma o seguinte: "a unidade e a identidade do fenômeno tátil não surgem através de nenhuma síntese de reconhecimento por meio do conceito" (KANT, 2002, p. 369).9 Ademais, acrescenta, não alcançamos constantes perceptivas por meio de induções, pois: “é impossível aqui supor que a interpretação se apoie em qualquer indução explícita" (KANT, 2002, p. 366). Não obstante, Merleau-Ponty conclui apressadamente que as constantes perceptuais só podem ser explicadas quando assumirmos que o corpo do agente é o invariável nas alterações: "trata-se de uma constância-para-meu-corpo, uma invariante de seu comportamento total" (MERLEAU-PONTY, 2002, p. 370).

Não restam dúvidas de que os nossos sistemas cognitivos percebem constantes perceptuais independentemente

\footnotetext{
${ }^{9}$ A crítica a Kant é, no entanto, inteiramente descabida. Kant nunca foi um intelectualista uma vez que afirma e reafirma reiteradas vezes que que sensibilidade humana é capaz de representar o mundo e, assim, induzir o agente a agir nesse mundo sem e independentemente de conceitos. O que está em jogo na síntese de recognição mediante conceitos não é a percepção de algo constante (garantida pela síntese de apreensão), mas antes o reconhecimento (Erkenntnis) dos objetos representados pelos sentidos como objetos constantes mediante conceitos empíricos e categorias.
} 
de qualquer "síntese de recognição mediante conceitos" que envolva reflexão, pensamentos, julgamentos e conceitos. Sistemas perceptivos operam independentemente de conceitos e de juízos. Entretanto, não me parece correto se afirmar que um mesmo tamanho, um mesmo matiz de cor, seja uma "constância-para-meu-corpo" como quer Merleau-Ponty.

Suponhamos a situação em que um predador rastreia a sua presa (um leopardo africano rastreando uma gazela Thompson na relva africana). Ora, se o predador se esgueira, ora se aproximando da presa, ora se afastando se necessário, mas o tamanho da presa é constante, a constante perceptual não pode está sendo determinada pelo corpo biológico do predador justamente porque a sua posição relativa à presa está mudando à medida em que se aproxima e se afasta. O que estaria determinado então a constante do tamanho da presa na percepção que dela faz o predador? Ora, só há uma única resposta cabível: a constante perceptual do tamanho da presa é determinada por processos computacionais no córtex. Segundo TYLER BURGE:

A subdeterminação das causas ambientais por registros proximais torna a formação de estados perceptuais sujeita a erros (...). A questão é esta: a formação de estados perceptivos constitui um certo tipo de ob- jetivação. Dado que um processo produz um estado perceptivo que especifica entidades ambientais, a formação de estados perceptuais envolve um tipo de objetivação. Essa objetivação é a formação de um estado que funciona para representar para além das características idiossincráticas do indivíduo. O objeto é o ambiente físico. A objetivação envolve uma certa distância do lugar ou idiossincrática. A objetivação reside nas maneiras pelas quais os sistemas perceptivos superam a subdeterminação. $\mathrm{O}$ sistema perceptivo distingue padrões codificados no registro sensorial que são provavelmente adventícios, ou idiossincráticos para quem percebe, de padrões que tendem a se correlacionar com aspectos específicos do ambiente. Quando o processamento perceptivo produz representação do ambiente físico, ele constitui a objetivação relevante. O registro sensorial é local e idiossincrático. Os estados perceptivos representam uma realidade além da estimulação proximal. (BURGE, 2014, pp. 398-399)

A objetivação na percepção é implementada por constantes perceptuais de forma inteiramente subliminar 
no córtex por processos computacionais descobertos por DAVID MARR (1982). Constantes perceptuais são capacidades perceptivas para representar sistematicamente algum dado particular ou atributo como aquele muito particular ou atributo sob variações mais diversas no registro da estimulação proximal. Em uma constante perceptual, um sistema perceptivo pode representar algum dado aspecto do ambiente físico como aquele aspecto de diferentes perspectivas perceptivas, produzido por diferentes estímulos próximos.

De tal processo de objetivação podemos extrair várias conclusões, todas contrárias ao enactivismo (ao menos na sua forma inicial tal como proposta por Varela e colegas). Primeiro, o que resulta de tais processos de objetivação é justamente uma representação nãoconceitual de um objeto/propriedade. Segundo, a objetivação subliminar nos permite eliminar de vez um construtivismo sem sentido de que "o mundo e o agente se especificam mutuamente" (sic.). Mas o ponto fundamental é o seguinte. A objetivação demonstra que a representação de uma constante perceptual precede e torna possivel a ação do agente e não o inverso como sugerem os enativistas. Para podermos reconhecer um objeto como um "proporcionador" ("affordance") de uma ação possível, devemos primeiro ser capazes percebê-lo como algo com um tamanho constante a despeito das variações ambientais. Mas justamente isso significa dizer que não há proporcionadores sem representações dos mesmos.

Como usual em filosofia, imagino que os enativistas ainda não se deram por vencidos; afinal se Marr foi um gênio da psicologia cognitiva, JAMES J. GIBSON (1986) também teria sido um grande nome na área e foi ele o primeiro sugerir que perceber é algo como agir com proporcionadores ao invés de representar o mundo. $\mathrm{O}$ impacto da psicologia Gibsoniana no enactivismo pode ser mensura pela coletânea editada por varela e Thomson (1991). Entretanto a ciência empírica da visão avançou tremendamente nas últimas décadas. Existem literalmente centenas de trabalhos bem detalhados matematicamente em muito bem sustentados empiricamente da visão dentro de uma armação conceitual representacionista. E se deixarmos de lado, os trabalhos com ênfase na matemática computacional, o número de trabalhos publicados chega à casa dos $m$ milhares. Para desbancar essa verdadeira avalanche, os adeptos da psicologia de Gibson e do enactivismo teriam que apresentar trabalhos tão bem empiricamente e matematicamente detalhados como os representacionistas.

Os muitos experimentos de Nicolelis e colegas põem por terra a tese de Merleau-Ponty da "constância-parameu-corpo". Em um dado experimento (2013) foram desenvolvidos sensores que captaram essas atividades nos ratos, decodificaram e transmitiram para 
outros ratos, onde foram decodificadas e compreendidas. Ele descreve o seu experimento nos seguintes termos:

Uma interface cérebro-cérebro (BTBI) permitiu uma transferência em tempo real de informações sensório-motoras comportamentais significativas entre os cérebros de dois ratos. Neste BTBI, um rato "codificador" executava tarefas sensório-motoras que exigiam que ele selecionasse duas opções de estímulos táteis ou visuais. Enquanto o rato codificador executava a tarefa, amostras de sua atividade cortical eram transmitidas para áreas corticais correspondentes de um rato "decodificador" usando microestimulação intracortical (ICMS). O rato decodificador aprendeu a fazer seleções comportamentais semelhantes, guiado apenas pelas informações fornecidas pelo cérebro do rato codificador. Esses resultados demonstraram que um sistema complexo foi formado pelo acoplamento dos cérebros dos animais, sugerindo que os BTBIs podem permitir que díades ou redes de cérebros dos animais troquem, processem e armazenem informações e, portanto, servir como base para estudos de novos tipos de interação so- cial e para dispositivos de computação biológica. (NICOLELIS e colegas, 2013, p. 1)

Pelo experimento, um rato recebia comandos mentais de outro e acionava uma alavanca. O rato codificador era recompensado se o outro realizasse a tarefa de forma correta. Foi esse duplo estímulo que levou à colaboração entre os dois ratos. Quando o segundo rato errava a alavanca, o primeiro tratava de reformular a ordem, sendo mais atento e enviando ordens mais precisas. Ora, o que podemos extrair desse experimento? No experimento, o tamanho da alavanca era uma constante perceptual para os ratos envolvidos, independentemente dos seus corpos! O tamanho da alavanca não é uma constância para esse ou para aquele corpo de rato. O invariante constitutivo da constante perceptual tátil não é "constância-parameu-corpo-de-rato". Constitutiva é a rede neuronal instanciada por um ou mais corpos dos ratos!

O segundo experimento que gostaria de mencionar é o experimento que Nicolelis realizou com uma rede de primatas (2015). Eles aprenderam a utilizar a interface em tarefas bem mais complexas. Dois ou mais primatas passaram a controlar recursos artificiais mediante um avatar. Nas palavras de Nicolelis e colegas:

Tradicionalmente, as interfaces cérebro-máquina (IMC) ex- 
traem comandos motores de um único cérebro para controlar os movimentos de dispositivos artificiais. Aqui, apresentamos um Brainet que utiliza a atividade cerebral em larga escala (VLSBA) de dois (B2) ou três (B3) primatas não humanos para se envolver em um comportamento motor comum. Um B2 gerou movimentos 2D de um braço de avatar, onde cada macaco contribuiu igualmente para as coordenadas $\mathrm{X}$ e Y; ou um macaco controlava totalmente a coordenada X e o outro controlava a coordenada Y. Um B3 produzia movimentos de braço no espaço 3D, enquanto cada macaco gerava movimentos em subespaços $2 \mathrm{D}(\mathrm{X}-$ $\mathrm{Y}, \mathrm{Y}-\mathrm{Z}$ ou $\mathrm{X}-\mathrm{Z}$ ). Com o treinamento de longo prazo, observamos um aumento da coordenação do comportamento, aumento das correlações na atividade neuronal entre diferentes cérebros e modificações na representação neuronal do plano motor. No geral, o desempenho do Brainet melhorou devido ao comportamento coletivo dos macacos. Esses resultados sugerem que os cérebros dos primatas podem ser integrados em um Brainet, que se auto-adapta para atingir um objetivo motor comum. (NICOLELIS e colegas,

\section{5, p. 1)}

Depois de controlar o avatar com a mente, conseguiram processar um feedback táctil. Assim, com corpos distintos e separados no espaço, um dos macacos tinha experiência tátil com algum objeto e imediatamente passava do conhecimento adquirido para o parceiro. A primeira conclusão que se extrai desse experimento é a mesma do experimento anterior: um corpo não é necessário para a experiência tátil, mas antes aquilo que o enativista quer negar: uma rede neuronal instanciada em um ou mais corpos. É essa possibilidade de adicionarmos "dispositivos artificiais" ao cérebro funcionando que passa a representa-los tais como membros orgânicos do corpo que denomino aqui the "corpos estendidos". O binômio é uma clara alusão ao célebre artigo de DAVID CHALMERS e ANDY CLARK, “a mente estendida" (1998). Nada do que digo aqui contradiz a tese original da "mente estendida". Entretanto, a tese que quero fazer valer é ainda mais radical e, penso eu, interessante. É relativamente trivial reconhecermos que dispositivos artificiais estendem a mente para além dos limites do crânio. Mas o mais interessante me parece ser o seguinte: pelo experimento de Nicolelis e colegas, podemos concluir que é o próprio corpo vivo (Leib) que se estende para além dos limites dados pelo corpo biológico. Podemos adicionar dispositivos artificiais ao 
representa-los como membros do nosso corpo tal como adicionamos acessórios aos nossos computadores via Bluetooth. Os primatas "incorporam" os dispositivos como partes do seu próprio corpo tal como adicionamos fones sem fio ao nosso computador fazendo apenas ajustes nas "preferências do sistema".

Mas o experimento mais significativo de Nicolelis e colegas (2013) é aquele que coloca uma pá de cal em todas as formas de enactivismo. Nele Nicolelis e colegas chegam à conclusão que a representação cerebral do próprio corpo, o chamado esquema corporal, antecede e constitui a percepção tátil dos objetos:

A representação cerebral do corpo, chamada de esquema corporal, é suscetível à plasticidade. Por exemplo, sujeitos que experimentam uma ilusão de mão de borracha desenvolvem um senso de propriedade de uma mão de manequim quando a veem sendo tocada enquanto estímulos táteis são aplicados simultaneamente em sua própria mão. Aqui, a base cortical de tal modalidade foi investigada através de gravações simultâneas de conjuntos neuronais corticais primários (isto é, S1) e motores (isto é, M1) enquanto dois macacos observaram um braço de avatar sendo tocado por uma bola virtual. Após um período em que os to- ques virtuais ocorreram sincronizadamente com as escovadas físicas dos braços dos macacos, os neurônios em S1 e M1 começaram a responder aos toques virtuais aplicados sozinhos. As respostas ao toque virtual ocorreram 50 a $70 \mathrm{~ms}$ mais tarde do que ao toque físico, consistente com o envolvimento de vias polissinápticas que ligam o córtex visual a S1 e M1. Propomos que S1 e M1 contribuam para a ilusão da mão de borracha e que, aproveitando a plasticidade dessas áreas, os pacientes possam assimilar membros neuroprostéticos como partes de seu esquema corporal. (NICOLELIS e colegas, 2013, p. 1, meus grifos)

Qual é a conclusão mais plausível que esse experimento de Nicolelis impõe? $\mathrm{O}$ corpo que importa à cognição não é um "Körper", mas um "Leib". Essa é uma distinção introduzida pelo filósofo e antropólogo HELMUTH PLESSNER nos anos vinte. Ele formula apresenta a distinção em 1920escrito em colaboração com o psicólogo behaviorista holandês FREDERICK J. BUYTENDIJK (conferir C. E. M. STRUYKER BOUDIER 1993). Paradoxalmente, essa distinção é incorporada por ninguém menos que Merleau-Ponty a fonte inspiradora da primeira fase do enactivismo (conferir MERLEAU- 
PONTY 1966; 1976). O corpo que interage com o mundo e outros corpos não é o corpo biológico (Körper), mas o corpo vivo (Leib) que só vem a existir quando devidamente representado como um esquema corporal pelo próprio cérebro. Para usar do jargão de Varela e cia, o mundo é em si "dado", existente independentemente das nossas representações. O que não é "dado" é o nosso próprio corpo (Leib) que deve ser constituído por representações subliminares que o nosso cérebro faz do nosso corpo biológico e tudo mais que se associe ao nosso corpo biológico. E tal representação cerebral de algo como o próprio corpo é plástica ou maleável como os experimentos de Nicolelis assinalam.

Casos patológicos conhecidos suportam a mesma suposição como, por exemplo, o da dor no membro fantasma (amputado). Quase todas as pessoas que tiveram um membro amputado ou o um nervo removido relatam ter experimentado algum tipo de membro fantasma, mas apenas alguns relatam dor persistente em membro fantasma. Aqueles que o fazem, no entanto, relatam que a dor é muito forte - geralmente não é aliviada por medicamentos ou dispositivos implantados. O membro amputado não mais existe biologicamente, no entanto, ele é ainda representado pelo cérebro como parte do esquema corporal. Pessoas nessa condição reportam sentir dor no membro ausente porque tal membro esta- ria "preso". A terapia mais auspiciosa é simples e sem custo: utiliza-se um espelho. Embora neurologistas do século 19, tenham buscado o tratamento com espelho, versões modernas só foram desenvolvidas por VILAYANUR S. RAMACHANDRAN na Universidade da Califórnia, San Diego.

Em um trabalho recente, JACK TSAO e colegas (2007) descrevem uma das melhores tentativas de elucidar o verdadeiro valor da terapia do espelho para dor em membros fantasmas. Os pesquisadores escolheram aleatoriamente 22 amputados de membros inferiores com dor fantasma em um dos três grupos:

1. Movimentos de espelho: os pacientes observavam a imagem refletida de seu pé intacto em um espelho enquanto moviam os dois pés simultaneamente. (Obviamente, os amputados não podem mover o pé perdido, mas podem mover o pé fantasma.)

2. Movimentos do espelho coberto: os pacientes realizavam os mesmos movimentos, mas o espelho estava coberto para que não vissem um membro em movimento.

3. Movimentos imaginários: sujeitos retratados mentalmente movendo o pé fantasma, com os olhos fechados.

Todos os pacientes realizaram $15 \mathrm{mi}$ nutos por dia de sua terapia designada 
e registraram o número, duração e intensidade dos episódios de dor. Após quatro semanas, houve duas descobertas principais. Em primeiro lugar, a dor diminuiu significativamente em todos os seis pacientes que realizaram os movimentos do espelho, com a redução média, conforme relatado em uma escala de 100 pontos, sendo de 30/100 para cerca de 5/100. Em segundo lugar, três em cada seis pacientes no grupo de movimentos do espelho coberto e quatro em cada seis pacientes no grupo de movimentos imaginários pioraram, não melhoraram.

A conclusão mais plausível desses experimentos é a de que os movimentos do espelho diminuem a dor do membro fantasma. Por que o tratamento se mostrou exitoso? Bom, não há uma resposta clara para isso uma vez que não sabemos como funciona o cérebro. Mas uma coisa é líquida e certa e é o que importa para a discussão de artigo. De uma forma ou de outra, o cérebro através do espelho passou a representar o membro fantasma de forma diferente. Mais uma vez, quem manda no espetáculo não é o corpo biológico (Körper) mas o corpo vivo (Leib), ou seja, o que quer que seja que o cérebro venha integrar ao esquema corporal.

Casos não patológicos de transexualidade corroboram a mesma distinção entre corpo vivo (Leib) e corpo biológico (Körper). Essas pessoas se dizem "aprisionadas" no seu corpo biológico. Eles (Elas) se sentem mulheres/homens em corpo "estranho" de homem/mulher! Há inúmeros outros exemplos (de natureza patológica), me limitarei apenas a mais um: casos de distúrbios alimentares. Todo anoréxico se sente "obeso" no espelho, mesmo que ele esteja tal como um sobrevivente de um campo de concentração nazista! Moral da história: não é o corpo biológico (Körper) que constitui a percepção de objetos mundanos e dos estados de terceiros nem a auto-percepção, mas pelo contrário, é a percepção do corpo biológico como próprio (Leib) que torna possível a percepção de objetos e de estados mentais de terceiros.

Dito isto, é forçoso concluirmos que o enactivismo e a chamada perspectiva da segunda pessoa nada têm de recomendável. Tudo se resume a um modismo ideológico que revive o behaviorismo de Wittgenstein e outros. A única tese que resta de pé (nunca negada pelos cognitivistas) é a seguinte. Estados mentais elementares de terceiros são conhecidos de forma direta, ou seja, sem o auxílio de reflexões, juízos, inferências, teorizações e simulações mentais. Na próxima seção buscarei uma resposta para esse fenômeno que tomo aqui como um fato empírico.

\section{Modelo Alternativo}

Nas últimas décadas, Dretske foi o primeiro a ter a ideia de que cognição da mente de terceiros seria direta (1973). 
Antecipando-se a Gallagher em muitas décadas, Dretske sustentava, no entanto, que de fato ninguém poderia perceber diretamente a alegria, a raiva etc. de terceiros sob a forma da consciência de objeto (object-awareness). Só poderíamos "perceber" diretamente o fato de que alguém está alegre (fact-awareness). A primeira seria uma relação entre uma pessoa e uma coisa, enquanto a última teria conteúdo de uma crença. Há inúmeros exemplos de percepção de fatos: percebemos (o fato) que alguém é rico sem perceber a sua riqueza, ou percebemos que (o fato) uma determinada barra de metal está quente sem perceber o calor; percebemos (o fato) que o taque de gasolina está vazio, percebendo o ponteiro no painel do carro. Mutatis mutandis, poderíamos perceber (o fato) que o outro está feliz, sem perceber a alegria alheia (1969 e 1973). O ponto crucial da sua posição em 1973 era a ideia que a percepção da conduta de terceiros seria um indicativo mais do que confiável sobre o fato de que tais pessoas se encontram nos estados mentais respectivos em razão da relação nomológica que une os segundos aos primeiros, sustentada por contrafactuais confiáveis. Por exemplo, o bebê não estaria sorrindo para a sua mãe em condições normais caso não mãe não estivesse também sorrindo.

Em 1995, reapresenta a mesma ideia, de uma forma bem mais elaborada, entretanto, como um modelo de introspecção: "a percepção deslocada ou se- cundária" (displaced perception). Mas o que é uma percepção deslocada antes de mais nada? De acordo com Dretske, é "perceber que algo acontece (factawareness) quando se vê outra coisa (object-awareness)" (DRETSKE, 1995, p. 41). Por exemplo, estou diretamente ciente de que o carteiro está batendo à minha porta (fact-awarenes) ao ouvir meus cães latindo de uma determinada maneira (object-awareness). Percebo diretamente que o tanque de gasolina do meu carro está vazio (fact-awareness) ao perceber a posição do medidor no painel do meu carro (object-awareness). Mutatis mutandis, percebo diretamente que estou experimentando o azul (factawareness) porque estou consciente de um objeto que instancia a propriedade de ser azul (object-awareness).

Duas teses são dignas de nota a respeito do modelo proposto. Antes de mais nada, é importante se destacar que a ideia de percepção deslocada ou secundária de Dretske se baseia na suposição controversa de que nossas experiências perceptivas têm um conteúdo representacional (content view). Dretske sustenta que todos os fatos mentais seriam fatos representacionais, salientando, no entanto, que nem todos fatos sobre representações seriam fatos mentais. Assim, estou ciente de que (fact-awareness) estou realizando uma experiência de azul ao perceber algo azul porque a minha experiência de algo azul representa a instanciação da propriedade azul. 
Mas ainda mais controversa é a segunda suposição. Para reconhecer que estou realizando a experiência de azul (fact-awareness) ao perceber algo azul (object-awareness), eu teria que possuir o próprio conceito de ordem superior de representação. Mais uma vez, para reconhecer que estou realizando a experiência de azul (fact-awareness) ao perceber algo azul (object-awareness), eu teria que reconhecer no objeto azul percebido uma representação. Em outras palavras, eu teria que representar a representação do azul como uma representação. Esse modelo sucumbe por completo ao intelectualismo: ele parece envolver conceitos mentais altamente sofisticados e uma forma de inferência indutiva (que Dretske negava).

Entretanto, mesmo o modelo de 1973 sobre o conhecimento direto de estados mentais elementares de terceiros padece dos mesmos problemas. Em primeiro lugar, a despeito do que afirma o próprio autor: o bebê, ao perceber que a mãe está irada, percebendo sua expressão facial de ira, ele estaria realizando uma inferência indutiva. A criança teria aprendido a correlacionar a percepção da expressão facial da mãe com o conhecimento de que a mãe está irada. Ora, mas se isso for correto, primeiro, a percepção secundária não é "direta", mas indireta, ou seja, um caso clássico de indução empírica. Os inúmeros exemplos fornecidos por Dretske (na grande maioria de instrumentos de medição) vão nessa direção: sei que o carteiro está à minha porta porque ouço meus cães latirem. Ora, tive que aprender a relacionar determinados latidos dos meus cães com o fato do carteiro estar presente com base em experiências passadas: sempre (ou quase sempre) que meus cães latiam de uma determinada forma, o carteiro estava a bater à porta. Nesse e em outros casos, a confiabilidade vem da experiência passada que justifica a indução empírica.

No entanto, a despeito das críticas, ainda creio que o insight de Dretske está correto: se há "percepção" direta dos estados de terceiros, esta não pode ser uma "percepção" em sentido usual em que percebemos objetos mediante os nossos sentidos, mas tem que ser entendida uma "percepção secundária" de fatos, que aqui, para evitar malentendidos desnecessários, prefiro designar por "cognição". A tese a ser defendida reza então que conhecemos diretamente os estados mentais elementares de terceiros sem o auxílio de inferências, teorizações e simulações.

Dito isso, a primeira coisa que nos cabe suprimir do modelo original de Dretske é a ideia inaceitável de que o bebê saiba, por experiências passadas, que a expressão facial da sua mãe seja um indicativo confiável (uma evidência) que lhe permita julgar (intelectualismo) que a mãe está irada. Com efeito, essa hipótese não tem nada de absurda quando pensamos em estados mentais bem mais complexos. Entretanto, estamos considerando aqui ape- 
nas estados mentais elementares. Consequentemente, devemos suprimir do modelo original de Dretske a ideia de que o bebê possua conceitos sofisticados como ira, tristeza, alegria, etc.

Aqui estamos às voltas com uma tese essencial. Pelo que vimos, os interacionistas assumem que a relação entre o bebê e as expressões faciais da sua mãe seria uma relação de contato epistêmico imediato (acquaintance). Não caberiam, portanto, equívocos por parte do bebê quanto às expressões faciais da sua mãe. Ora, nada me parece mais contraintuitivo! Mesmo que a relação cognitiva seja direta, nunca podemos excluir a priori a possibilidade de equívocos. O Bebê percebe erroneamente a expressão facial da mãe como de descontentamento quando a bem da verdade a mãe apresenta uma expressão social de censura. A única forma de captarmos a possiblidade de erros perceptuais é supondo que o bebê apresenta a expressão facial da mãe com determinadas condições de veridicidade. É importante se destacar que tal conteúdo, embora conceitual é rudimentar. Reiterado o que já disse, o mais plausível aqui supormos que muito cedo o bebê aprende a conceituar as expressões faciais da mãe como expressões de aprovação e reprovação, contentamento e descontentamento. E para isso, é óbvio que o bebê tenha que ter apreendido (como os cães) a correlacionar expressões faciais dos seus cuidadores com as condutas do mesmo. Entretanto, esse aprendizado não dará azo a induções empíricas. Por quê? Porque o bebê não necessita tomar a expressão facial da mãe como um indicativo confiável (premissa) de que a mãe está descontente. $\mathrm{E}$ é nesse sentido que seu conhecimento é direto.

O primeiro passo consiste em assumir uma concepção externista de conhecimento. Contra Dretske (1995), não precisamos supor que que o bebê perceba a face da mãe descontente como uma evidência para a crença de que a mãe está descontente. Por essa razão, não há crença conectivas que careça de justificação em primeira pessoa tal como em uma indução empírica. A representação do bebê da expressão facial da mãe constitui apenas uma garantia confiável de que a mãe está descontente. Ora, isso exclui por definição a possibilidade de que o bebê esteja fazendo alguma inferência indutiva. Mas o processo também é automático: o bebê representa a expressão facial da mãe de forma consciente (input) e, mesmo sem refletir e inferir, reconhece tal expressão como um descontentamento de forma subliminar (output).

\section{Conclusão}

Creio ter demonstrado com base em inúmeros argumentos e exemplos que percebemos de fato diretamente estados mentais elementares de terceiros. 
Trata-se de um processo epistemológico que é ao mesmo tempo automático e confiável. É confiável no sentido externista (epistemológico) de não envolver nenhuma reflexão, interpretação ou justificativa epistêmica. Mas é ao mesmo tempo automático porque é implementado no cérebro no âmbito das representações subliminares. Assim, por exemplo, uma criança toma ciência de que a sua mãe está raivosa (factawareness) quando ela percebe uma expressão facial típica como um input sensorial cujo output automático é o reconhecimento do fato de que a mãe está com raiva.

\section{Referências}

BARON-COHEN, S., LESLIE, A.M., FRITH, U. “Does the autistic child have a 'theory of mind'?, Cognition 21, 1985, pp. 37-46.

BOUDIER, H. S. "Helmuth Plessner als philosophischer Wegweiser für F. J. J. Buytendijk." Man and World 26, 1993, pp. 199-207.

DRETSKE, F. Seeing and Knowing. London: Routledge Kegan Paul, 1969.

. "Perception and other minds." Noûs 7, 1973, pp. 34-44.

. Naturalizing the Mind. Cambridge, MA: The MIT Press, 1995.

_-. "The Mind's Awareness of Itself." Philosophical Studies 95 (1), 1999, pp. 103-124.

CAMPBELL, J. Reference and Consciousness. Oxford: Oxford University Press, 2002.

CASSAM, Q. The Possibility of Knowledge. Oxford: Clarendon Press, 2007.

CARRUTHERS, P. “Perceiving Mental States.” Consciousness and Cognition 36, 2015, pp. 498-507.

CHAN, BL, WITT R, CHARROW AP, MAGEE A, HOWARD, R, PASQUINA PF, HEILMAN KM, TSAO JW. "Mirror therapy for phantom limb pain." N Engl J Med. Nov 22, 357(21), 2007, pp. 2206-7.

CHIHARA, C. Fodor, Jerry A. "Operationalism and ordinary language: A critique of Wittgenstein." American Philosophical Quarterly 2 (4), 1965, pp. 281-95.

CLARK, A. CHALMERS David J. “The extended mind.” Analysis 58 (1), 1998, pp.7-19.

DE JAGHER, H. "Social understanding through direct perception? Yes, by interacting." Consciousness and Cognition, 18, 2009, pp. 535-542.

DI PAOLO, E. “Extended Life.” Topoi 28, 2009, pp. 9-21.

GALLAGHER, S. "Understanding interpersonal problems in autism: Interaction theory as an alternative to theory of mind." Philosophy, Psychiatry, and Psychology 1, 2004, pp. 199-217.

. "Direct perception in the intersubjective context." Consciousness and Cognition, 17, 2008, pp. 535-543.

. "In defense of phenomenological approaches to social cognition: Interacting with the critics." Review of Philosophy and Psychology, 3 (2), 2012, pp. 187-212.

GALLAGHER, S., BOWER, M. "Making Enactivism even more Embodied." Avant 5, 2014, pp. 232-247.

GIBSON, J. J. The Ecological Approach to Visual Perception. Hillsdale, NJ: Lawrence Erlbaum Associates, 1986.

GOLDMAN, A. I. e SRIPADA, C. S. "Simulationist models of face-based emotion recognition." Cognition, 94, 2005, pp. 193-213.

GOPNIK, A., WELLMAN, H. "The ,Theory-Theory'." Em L. HIRSCHFIELD e S. GELMAN (Eds.): Domain specificity in culture and cognition, 1995, New York: Cambridge University Press.

GOPNIK, A., MELTZOFF, A. Words, thoughts, and theories. Cambridge, Mass.: Bradford, MIT Press, 1997.

GORDON, R. "Folk Psychology as Simulation." Mind and Language 1, 1986, pp. 158-171.

GREEN, M. "Perceiving emotions." Proceedings of the Aristotelian Society Supplementary Volume 84, 2010, pp. 45-61.

HEAL, J. "Replication and Functionalism." Em: J. BUTTERFIELD (ed.). Language, Mind, and Logic. Cambridge: Cambridge University Press, 1986.

HUSSERLS, E. Cartesian Meditations: An Introduction to Phenomenology. Trans. D. CAIRNS. Dordrecht: Kluwer Academic Publishers, 1995.

HUTTO, D. E MYRIN, E. Radicalizing Enactivism: Basic Minds without Content. Cambridge, MA: MIT Press, 2013.

KRUEGER, J. "Seeing mind in action." Phenomenology and the Cognitive Sciences 11, 2012, pp. 149-173.

MARR, D. Vision: A Computational Investigation into the Human Representation and Processing of Visual Information. San Francisco: W. H. Freeman, 1982. 
MCDOWELL, J. Having the World in View. Cambridge, MA: Harvard University Press, 2009.

MCNEILL, W. E. S. "Embodiment and the perceptual hypothesis.” The Philosophical Quarterly 62, 2012 , pp. 569-591.

MERLEAU-PONTY, M. Phänomenologie der Wahrnehmung. Berlin, de Gruyter, 1966.

Die Struktur des Verhaltens. Berlin: de Gruyter, 1976.

. Phenomenology of Perception. Trans. D. Landes. London: Routledge, 1976.

NICHOLS, S. Mindreading. An integrated account of pretence, self-awareness and understanding other minds. Oxford: OUP, 2003.

NOË, A. Action in Perception. Cambridge, MA: The MIT Press, 2004.

-. "Real Presence." Philosophical Topics 33, 2005, pp. 235-264.

PAIS-VIERA, M., LEBEDEV, M., KUNICKI, C. E colegas. "A Brain-to-Brain Interface for Real-Time Sharing of Sensorimotor Information." Scientific Reports 3, 2013, pp. 13-19.

PLESSNER, H. "Untersuchungen zu einer Kritik der philosophischen Urteilskraft". Do mesmo autor, Gesammelte Schriften II: Frühere philosophische Schriften 2, ed. GÜNTHER D., MARQUARD, ODO., STRÖKER, E., 1981, pp. 7-321. Frankfurt am Main: Suhrkamp.

RATCLIFFE, M.J. Rethinking Commonsense Psychology: A Critique of Folk Psychology, Theory of Mind and Simulation. Basingstoke: Palgrave Macmillan, 2007.

REDDY, V. How infants know minds. Cambridge, Mass.: Harvard University Press, 2008.

STANLEY, J. E WILLIAMSON, T. “Knowing How.” The Journal of Philosophy 98.8, 2001, pp. 411-444.

SOLAINAM S., O’DOHERTY, J. E., WINANS, J.A., BLEULER, H., MIKHAIL, A., Miguel A. L. NICOLELIS, M.A.L. "Expanding the body schema in sensorimotor cortex." Proceedings of the National Academy of Sciences, 2013, pp. $1-6$.

SERALE, J. R. Intentionality. Cambridge: Cambridge University Press, 1983.

THOMPSON, E. Mind in Life: Biology, Phenomenology, and the Sciences of Mind. Cambridge, MA: Harvard University Press, 2007.

TRAVIS, C. "The silence of the senses." Mind 113, 2004, pp. 57-94.

--. "Review of Susanna Siegel, The Contents of Visual Experience." Philosophical Studies 163, 2013, pp. 837-846.

VARELA, F. J., THOMPSON, E., ROSCH, E. The Embodied Mind: Cognitive Science and Human Experience. Cambridge, MA: MIT Press, 1991.

ZAHAVI, D. "Empathy and direct social perception: a phenomenological proposal." Review of Philosophy and Psychology 2, 2011, pp. 541-558.

Recebido: $02 / 02 / 2021$

Aprovado: $12 / 03 / 2021$

Publicado: 30/04/2021 
